\title{
Does the breaking of adsorption-energy scaling relations guarantee enhanced electrocatalysis?
}

\author{
Govindarajan, Nitish ; García-Lastra, Juan M.; Meijer, Evert Jan ; Calle-Vallejo, Federico
}

\section{Published in:}

Current Opinion in Electrochemistry

Link to article, DOI:

10.1016/j.coelec.2018.03.025

Publication date:

2018

Document Version

Peer reviewed version

Link back to DTU Orbit

Citation (APA):

Govindarajan, N., García-Lastra, J. M., Meijer, E. J., \& Calle-Vallejo, F. (2018). Does the breaking of adsorptionenergy scaling relations guarantee enhanced electrocatalysis? Current Opinion in Electrochemistry, 8, 110-117. https://doi.org/10.1016/j.coelec.2018.03.025

\section{General rights}

Copyright and moral rights for the publications made accessible in the public portal are retained by the authors and/or other copyright owners and it is a condition of accessing publications that users recognise and abide by the legal requirements associated with these rights.

- Users may download and print one copy of any publication from the public portal for the purpose of private study or research.

- You may not further distribute the material or use it for any profit-making activity or commercial gain

- You may freely distribute the URL identifying the publication in the public portal 


\title{
Does the breaking of adsorption-energy scaling relations guarantee enhanced electrocatalysis?
}

\author{
Nitish Govindarajan, ${ }^{1}$ Juan M. García-Lastra, ${ }^{2}$ Evert Jan Meijer ${ }^{1}$ and Federico Calle- \\ Vallejo $^{3, *}$ \\ ${ }^{1}$ Van't Hoff Institute for Molecular Science and Amsterdam Center for Multiscale Modeling, Universiteit van Amsterdam, Science Park 904, \\ 1098 XH, Amsterdam, The Netherlands. \\ ${ }^{2}$ Department of Energy Conversion \& Storage, Technical University of Denmark, DK-4000 Roskilde, Denmark. \\ ${ }^{3}$ Departament de Ciència de Materials i Química Fisica \& Institut de Química Teòrica i Computacional (IQTCUB), Universitat de Barcelona, \\ Martí i Franqués 1, 08028 Barcelona, Spain.
}

Elsevier use only: Received date here; revised date here; accepted date here

\begin{abstract}
The adsorption energies of numerous species on homogeneous and heterogeneous catalysts scale linearly with each other. Such linear dependence lowers the degrees of freedom in multistep reactions, greatly simplifying computational electrocatalysis models. The downside of scaling relations is that they limit the efficiency of electrocatalytic reactions. For instance, the scaling relation between ${ }^{*} \mathrm{OOH}$ vs $* \mathrm{OH}$ supposedly limits the oxygen evolution and reduction reactions (OER, ORR): while the energetic separation of these intermediates should ideally be $2.46 \mathrm{eV}$, on most catalysts it is $\sim 3.20 \mathrm{eV}$. Thus, it is currently assumed that breaking such scaling relation might lead to significant enhancement of OER/ORR electrocatalysis. In this review, we evaluate this hypothesis using literature data. The analysis suggests that breaking the $* \mathrm{OOH}$ vs $* \mathrm{OH}$ scaling relation is a necessary yet insufficient condition to optimize OER/ORR electrocatalysts. Alternatively, we define a new descriptor: the electrochemical-step symmetry index (ESSI), the optimization of which effectively corresponds to low calculated overpotentials.
\end{abstract}

* Corresponding author. Tel.: +34 934021229; fax: +34 934021231; e-mail:f.calle.vallejo@ub.edu

\section{Brief introduction to scaling relations}

Since their discovery [1], adsorption-energy scaling relations have immensely contributed to the fields of catalysis and surface chemistry [2,3]. As they have been shown to exist between a broad range of adsorbates on homogeneous and heterogeneous catalysts, their insights have been extraordinarily useful in computational catalysis to rationalize activity trends [2,3]. Remarkably, they have also been used to build Sabatier-type activity plots, which guide experiments toward the discovery of new catalyst materials $[4,5]$. On facet $i$ of a given set of materials, adsorption-energy scaling relations between species 1 and 2 are defined as:

$\Delta G_{2}^{i}=A_{1,2} \Delta G_{1}^{i}+B_{1,2}^{i}$

While some authors attribute scalability to bondorder conservation theory [2,6], we explain it based 
on the connection between the electronic and geometric structure of materials and their adsorption behavior [7-9]. If $\Delta G_{1}^{i}$ and $\Delta G_{2}^{i}$ scale with each other and depend on a set of structural parameters $\left\{\omega_{j}\right\}$ as $\Delta G_{1}^{i}=g^{i}\left(\left\{\omega_{j}\right\}\right)+\beta_{1}^{i}, \Delta G_{2}^{i}=f^{i}\left(\left\{\omega_{j}\right\}\right)+\beta_{2}^{i}$, then:

$f^{i}\left(\left\{\omega_{j}\right\}\right)=A_{1,2} g^{i}\left(\left\{\omega_{j}\right\}\right)$

$$
B_{1,2}^{i}=\beta_{2}^{i}-A_{1,2} \beta_{1}^{i}
$$

According to Equation (2), if two species scale with each other, their adsorption energies are proportionally modulated by the same parameters and $A_{1,2}$ is the proportionality constant. $A_{1,2}$ is a dimensionless, surface independent slope, calculated applying electron-counting rules to the adsorbates $[7,8]$. For instance, the $* \mathrm{OH}$ vs $* \mathrm{O}$ scaling has $A_{O / O H} \approx \frac{1}{2}$, as the $\mathrm{O}$ atom in $* \mathrm{OH}$ lacks one electron to reach the octet and $* \mathrm{O}$ lacks two. However, scaling relations are not limited to species bound via the same atom, so that e.g. ${ }^{*} \mathrm{O}$ scales well with ${ }^{*} \mathrm{~S}[8]$.

Recently, $\mathrm{Su}$ et al [7] identified several parameters belonging to $\left\{\omega_{j}\right\}$ : outer electrons, work function, excess charge, d-band center, integrated crystal orbital overlap population, integrated crystal orbital Hamilton population. They also showed that while $A_{1,2}$ is typically positive, negative slopes are observed between covalent and ionic adsorbates [7].

In Equation (3), the offset $B_{1,2}^{i}$ depends on the slope, $\beta_{1}^{i}$ and $\beta_{2}^{i}$. Based on structure-energy relationships [9-15], one can conclude that $\beta_{1}^{i}, \beta_{2}^{i}$ and the offset depend on the coordination of facet $i$ [9,14]. A particular case is $A_{1,2}=1$, as a single offset describes the data for all facets and materials (the scaling of $* \mathrm{OOH}$ vs $* \mathrm{OH}$ in Figure 1 is a salient example, other examples include ${ }^{*} \mathrm{CHO}$ vs $* \mathrm{CO}$ and ${ }^{*} \mathrm{Cl}$ vs $\left.* \mathrm{~F}\right)[8,9,14,16]$. Note in passing that there are also scaling relations between adsorption energies and other types of energetics, namely bulk energies of formation [17] or adsorption-site stability [18].

From a catalysis perspective, the existence of scaling relations entails a simple but far-reaching idea: if (at least some of) the adsorption energies are linearly dependent, the degrees of freedom available for optimizing catalytic sites are lower than the number of different adsorbed species [19,20].

From a modelling perspective this is an advantage, as models of catalytic reactions can, and have been, largely simplified [5,6]. However, this is considered to be a limitation for the design of enhanced materials, as linear dependence may preclude further optimization of catalytic activities [6]. In other words, the energetic connection between adsorbates is allegedly deleterious in catalysis.

Thus, it is believed that breaking scaling relations may lead to enhanced catalysts. This idea is extended in electrocatalysis, especially for $\mathrm{CO}_{2}$ reduction [21], oxygen reduction reaction (ORR) and oxygen evolution reaction (OER) [19,20]. For the latter two, it is considered that the scaling between the adsorption energies of $* \mathrm{OOH}$ and $* \mathrm{OH}$ might be the origin of the high overpotentials observed experimentally.

On the example of the OER catalyzed by a wide variety of materials, we show here that breaking the scaling between $* \mathrm{OH}$ and $* \mathrm{OOH}$ is a necessary yet insufficient condition to optimize catalytic active sites. As such, breaking it may not necessarily lead to high OER activities, and materials that do not break this scaling might as well be highly active. We will show that a more robust description of OER activity is provided by the electrochemical-step symmetry index (ESSI), an energetic descriptor defined and tested here, which can also be used for other reactions such as the ORR. 
1. Scaling relations in oxygen evolution electrocatalysis

We assume that the OER $\left(2 \mathrm{H}_{2} \mathrm{O} \rightarrow \mathrm{O}_{2}+4 \mathrm{H}^{+}+4 e^{-}\right.$, $E^{0}=1.23 \mathrm{~V}$ ) proceeds as $[19,22]$ :

$*+\mathrm{H}_{2} \mathrm{O} \rightarrow{ }^{*} \mathrm{OH}+\mathrm{H}^{+}+e^{-}$

${ }^{*} \mathrm{OH} \rightarrow{ }^{*} \mathrm{O}+\mathrm{H}^{+}+e^{-}$

${ }^{*} \mathrm{O}+\mathrm{H}_{2} \mathrm{O} \rightarrow{ }^{*} \mathrm{OOH}+\mathrm{H}^{+}+e^{-}$

${ }^{*} \mathrm{OOH} \rightarrow{ }^{*}+\mathrm{O}_{2}+H^{+}+e^{-}$

The calculated OER overpotential $\left(\eta_{O E R}\right)$ is:

$\eta_{\text {OER }}=\max \left(\Delta G_{4}, \Delta G_{5}, \Delta G_{6}, \Delta G_{7}\right) / e-E^{0}$

Where $e$ is the (positive) electron charge. Given the scaling relations between the adsorption energies of ${ }^{*} \mathrm{O},{ }^{*} \mathrm{OH}$ and ${ }^{*} \mathrm{OOH}\left(\Delta G_{O}, \Delta G_{O H}, \Delta G_{O O H}\right)$ on numerous materials [1,9,19,20,23-29], only one of the three can be freely modified to optimize the reaction energies $\Delta G_{4}=\Delta G_{O H}, \Delta G_{5}=\Delta G_{O}-\Delta G_{O H}$, $\Delta G_{6}=\Delta G_{\text {OOH }}-\Delta G_{O}, \quad \Delta G_{7}=4.92-\Delta G_{\text {OOH }} \quad$ and thereby minimize $\eta_{\text {OER }}$. This is in line with the reduction in the degrees of freedom mentioned in the Introduction. Initially, it was proposed that a "fundamental" overpotential should arise from the scaling relation between $\Delta G_{O H}$ and $\Delta G_{O O H}$ [20].

This idea is based on four considerations:

(i) $* \mathrm{OH}$ and $* \mathrm{OOH}$ are separated by two proton-electron transfers (to verify that, sum Equations (4) and (7), or (5) and (6)).

(ii) For an ideal OER catalyst: $\Delta G_{4}=\Delta G_{5}=\Delta G_{6}=\Delta G_{7}=1.23 \mathrm{eV}$. Therefore, such catalyst has $\Delta G_{O}^{\text {ideal }}=2.46 \mathrm{eV}, \Delta G_{O H}^{\text {ideal }}=1.23 \mathrm{eV}$, and $\Delta G_{O O H}^{\text {ideal }}=3.69 \mathrm{eV}$.

(iii) The scaling relation of $\Delta G_{O O H}$ vs $\Delta G_{O H}$ should have a slope of $1\left(A_{O H / O O H} \approx 1\right)$, as the oxygen atom bound to the surface in $* \mathrm{OH}$ and $* \mathrm{OOH}$ lacks an electron to reach the octet in both cases $[9,19,20]$. Note, however, that the slope is typically smaller as a result of the increasing covalence of the metal-OOH bond for late-transition metal active sites [25,27].

(iv) Because $A_{\mathrm{OH} / \mathrm{OOH}} \approx 1$, a single line includes all materials, regardless of their composition and coordination $[9,19,20]$. The offset of such line is 


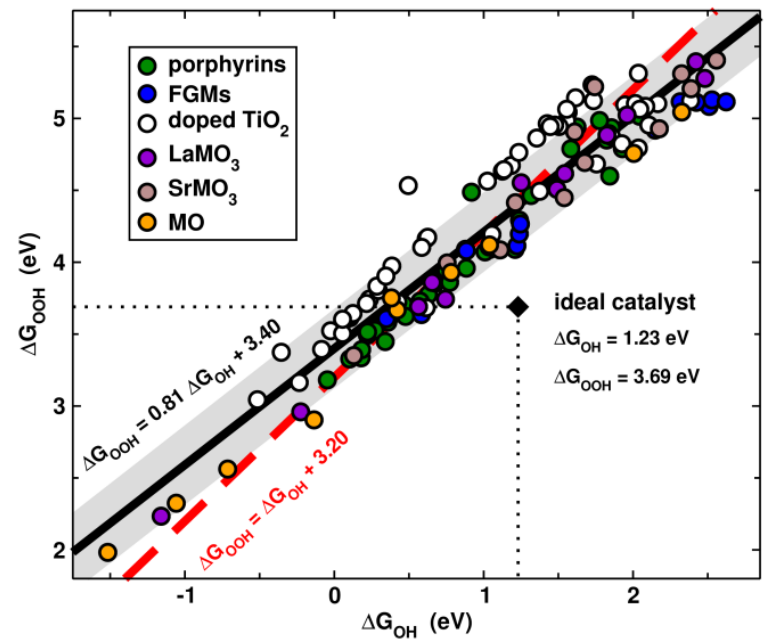

Figure 1. Adsorption-energy scaling relation between $* \mathrm{OH}$ and ${ }^{*} \mathrm{OOH}$ on various materials: $\mathrm{LaMO}_{3}$ and $\mathrm{SrMO}_{3}$ [17,19,27], monoxides MO [17,27], (un)doped $\mathrm{TiO}_{2}$ [26]), porphyrins [25], and functionalized graphitic materials (FGMs) [24,29]. The best fit to the points is provided (black line) together with the prediction made by Koper [20] and Man et al [19] (red line). A band around the black line covers an area of $\pm 1.5 \mathrm{MAE}$ around the best fit and contains $76 \%$ of the data. MAE: Mean absolute error, 0.17 $\mathrm{eV}$ in this case. $\$$ : ideal catalyst.

approximately $3.20 \mathrm{eV}$ (Figure 1), where data are included for porphyrins [25], functionalized graphitic materials (FGMs) [24,29], and four families of transition metal oxides (perovskites $\mathrm{LaMO}_{3}$ and $\mathrm{SrMO}_{3}$ [17,19,27], monoxides MO [17,27] and (un)doped $\mathrm{TiO}_{2}$ [26]). Note in Figure 1 that the ideal catalyst is ostensibly far from the main trend [19].

As the ideal separation between $* \mathrm{OOH}$ and $* \mathrm{OH}$ is $2.46 \mathrm{eV}$ but the actual separation is nearly constant on most materials and equal to $3.2 \mathrm{eV}$, a minimal $\eta_{O E R}=(3.20-2.46) \mathrm{eV} / 2 \mathrm{e}^{-}=0.37 \mathrm{~V}$ is suggested to result from scaling relations $[19,20]$. Note that this substantial overpotential adds at least an extra $30 \%$ requirement to the equilibrium potential of $1.23 \mathrm{~V}$ for water splitting.

Numerous works have confirmed such constant separation $[1,9,19,20,23-27,29]$ and significant efforts have been directed toward identifying materials with $\Delta G_{O O H}-\Delta G_{O H} \approx 2.46 \mathrm{eV}$.
In this regard, various strategies have been proposed to stabilize $* \mathrm{OOH}$ preferentially over $* \mathrm{OH}$ : three dimensional sites [24,30], doping [31], introducing hydrogen donor/acceptor functionalities and ligands [32], confinement effects [33], and electrolyte modification [25,34]. However, few examples exist where superior experimental catalytic activity may be attributed to the breaking of the $* \mathrm{OOH}$ vs $* \mathrm{OH}$ scaling [31]. Therefore, it is important to assess whether screening studies should merely focus on identifying catalysts with $\Delta G_{O O H}-\Delta G_{O H} \approx 2.46 \mathrm{eV}$, or if other criteria should be considered.

\section{Breaking the *OOH vs *OH scaling: panacea or partial solution?}

If the unideal constant separation between $* \mathrm{OH}$ and $* \mathrm{OOH}$ were to blame for (part of) OER inefficiencies, a sizable departure from $3.20 \mathrm{eV}$ to $2.46 \mathrm{eV}$ should correspond to a decrease in $\eta_{O E R}$. In other words, $\left(\Delta G_{O O H}-\Delta G_{O H}-2.46 \mathrm{eV}\right) / 2 \mathrm{e}^{-}$should tend to zero for the most active materials and be a large positive number for the least active ones.

Unfortunately, this is not observed in Figure 2 , where there is no straightforward correlation between $\eta_{O E R}$ and the departure from $3.2 \mathrm{eV}$ to 2.46 eV. Strikingly, a number of catalysts break the *OOH vs *OH scaling, as they display minimal deviations from $2.46 \mathrm{eV}$, but simultaneously possess high $\eta_{O E R}$.

This is the case of Au FGMs [24,29], for which $\Delta G_{O O H}^{A u-F G M}-\Delta G_{O H}^{A u-F G M}=2.49 \mathrm{eV} \quad$ but $\eta_{O E R}^{A u-F G M}=1.49 \mathrm{~V}$. Another example is $\mathrm{CaO}$ [17], which has $\eta_{O E R}^{C a O}=1.83 \mathrm{~V}$ in spite of $\Delta G_{\mathrm{OOH}}^{\mathrm{CaO}}-\Delta G_{\mathrm{OH}}^{\mathrm{CaO}}=2.72 \mathrm{eV}$. Based on the breaking of the $* \mathrm{OOH}$ vs $* \mathrm{OH}$ scaling relation, one would typically assume that these catalysts have negligible overpotentials, while those are in fact remarkably large. One can also find highly active materials that do not break the $* \mathrm{OOH}$ vs $* \mathrm{OH}$ scaling: consider 


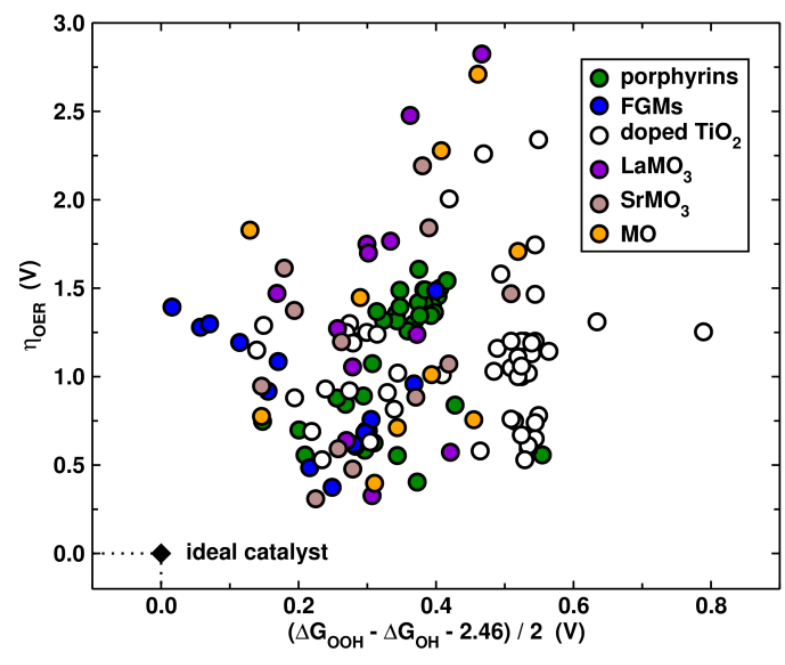

Figure 2. Calculated OER overpotentials $\left(\eta_{O E R}\right)$ for various electrocatalysts plotted as a function of their departures from the ideal $* \mathrm{OOH}$ vs $* \mathrm{OH}$ energetic separation of $2.46 \mathrm{eV}$. : ideal catalyst.

Mo-doped $\mathrm{TiO}_{2}$ (denoted $\mathrm{TiMoO}_{2}$ ), which has $\Delta G_{O O H}^{\mathrm{TiMoO}_{2}}-\Delta G_{\mathrm{OH}}^{\mathrm{TiMoO} \mathrm{O}_{2}}=3.52 \mathrm{eV}$ and $\eta_{\mathrm{OER}}^{\mathrm{TiMoO} \mathrm{O}_{2}}=0.53 \mathrm{~V}$ [26].

All these data and several others included in the Supporting Information lead us to conclude that breaking the $* \mathrm{OOH}$ vs $* \mathrm{OH}$ scaling may not necessarily guarantee enhanced OER electrocatalysis. This is because what defines an ideal OER catalyst is not that the sum of two of its reaction energies be $2.46 \mathrm{eV}$ but rather that all of them be $1.23 \mathrm{eV}$ [19].

\section{Electrochemical-step symmetry index (ESSI): a more robust descriptor of electrocatalytic activity}

If breaking the ${ }^{*} \mathrm{OOH}$ vs $* \mathrm{OH}$ scaling relation is a necessary yet insufficient condition to optimize OER electrocatalysis, what else is needed? The ideal catalyst sheds light into this matter: $\Delta G_{O}, \Delta G_{O H}, \Delta G_{O O H}$ are such that all reaction energies of the electrochemical steps are numerically equal to the equilibrium potential [19]. Thus, one can hypothesize that a measure of the departures of all "suitable" steps from ideality might help distinguish
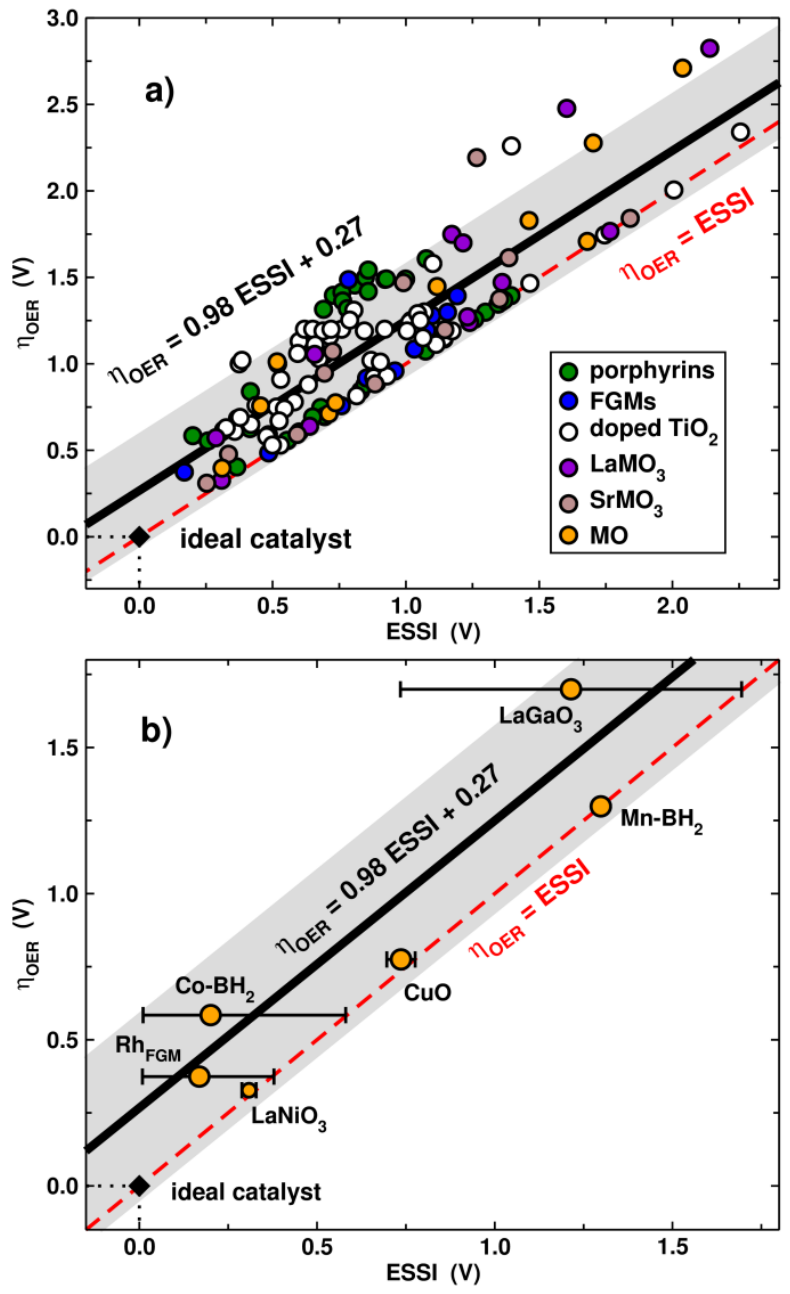

Figure 3. a) $\eta_{O E R}$ as a function of the electrochemical-step symmetry index (ESSI). The best linear fit is provided with a band around it covering an area of \pm 1.5 MAE (MAE $=$ $0.21 \mathrm{eV}$ ), which contains $86 \%$ of the data. The red line describes $\eta_{O E R}=E S S I$, the lower bound of which is the ideal catalyst ( $\bullet$. b) Selected data from (a) with range bars in the ESSI axis. Materials easy to optimize have null or wide bars, while narrow bars denote the opposite.

between high- and low-activity electrocatalysts. This is confirmed in Figure 3a, where ESSI and $\eta_{O E R}$ exhibit a good linear correlation. ESSI is defined in Equation (9) and applies only to steps for which $\Delta G_{i} \geq E^{0} \quad$ (denoted $\Delta G_{i}^{*}$ ), as only those can be potential-limiting: 


$$
E S S I=\frac{1}{n} \sum_{i}^{n}\left(\Delta G_{i}^{*}-E^{0}\right)
$$

To exemplify the use of Equations (8) and (9), consider $\mathrm{LaNiO}_{3}[17,19,27]: \Delta G_{4}$ to $\Delta G_{7}$ are $1.54,1.56,1.52$ and $0.30 \mathrm{eV}$. Therefore, $\eta_{O E R}^{\mathrm{LaNiO}_{3}}=(1.56-1.23) \mathrm{eV} / \mathrm{e}=0.33 \mathrm{~V}$ from $(6)$, and $E_{S S I}{ }^{\mathrm{LaNiO}_{3}}=(0.31+0.33+0.29) \mathrm{eV} / 3 \mathrm{e}^{-}=0.31 \mathrm{~V}$

from (7). Figure $3 b$ identifies $\mathrm{LaNiO}_{3}$ as an active OER material because its ESSI and $\eta_{O E R}$ are small, although $\Delta G_{\mathrm{OOH}}^{\mathrm{LaNi}_{3}}-\Delta G_{\mathrm{OH}}^{\mathrm{LaNO}_{3}}=3.07 \mathrm{eV}$.

There is an important feature of ESSI by construction (see Equations (8) and (9)): $E S S I \leq \eta_{O E R}$ . This is observed in Figure 3a in all cases. Materials for which $E S S I=\eta_{O E R}$ are $21 \%$ of the data in Figure $3 \mathrm{a}$ and fall over the red dashed line. For those, only one step in (4) to (7) is larger than $1.23 \mathrm{eV}$. Importantly, the ideal catalyst belongs to the line and represents its lower bound. Close to the line are materials for which the energies of all steps larger than $1.23 \mathrm{eV}$ are nearly identical.

As the best linear fit in Figure 3a has a slope close to 1 and an offset of $0.27 \mathrm{~V}$, most catalysts possess at least two reaction energies larger than $1.23 \mathrm{eV}$ and, in average, they are $0.27 \mathrm{eV}$ less negative than the potential-limiting step. In fact, $64 \%$ of the data possesses two steps larger than $1.23 \mathrm{eV}$ and only $14 \%$ possesses three.

\section{Optimizing OER catalysts with ESSI guidelines}

Figures 2 and 3 strongly suggest that catalyst optimization should not only focus on breaking the $* \mathrm{OOH}$ vs ${ }^{*} \mathrm{OH}$ scaling. Instead, the potentialdetermining steps for each material are to be considered. Since ESSI is defined as an average (Equation (9)), one can add bars to it showing the range they span, as depicted in Figure 3b. Materials with $E S S I=\eta_{O E R}$, such as $\mathrm{Mn}-\mathrm{BH}_{2}$ (a porphyrin with $\mathrm{BH}_{2}$ ligands and a Mn center), have null bars because only one of their steps, which is also the potentialdetermining step is larger than $1.23 \mathrm{eV}$. In principle, such materials are easy to optimize, as only one step needs to be altered to lower $\eta_{O E R}$. Materials close to $E S S I=\eta_{O E R}$ are normally difficult to optimize, as they have two $(\mathrm{CuO})$ or three $\left(\mathrm{LaNiO}_{3}\right)$ steps larger than $1.23 \mathrm{eV}$ and rather similar in energy, so that their bars are narrow. Altering the potentialdetermining step might simply cause another step to become potential-limiting, leaving $\eta_{O E R}$ practically unaltered. Finally, materials relatively far from the line where $E S S I=\eta_{O E R}$ have wide bars and are good candidates for optimization. This is the case of materials such as $\mathrm{Co}-\mathrm{BH}_{2}$ porphyrin, $\mathrm{Rh}_{\mathrm{FGM}}$ (functionalized graphitic materials with $\mathrm{Rh}-\mathrm{N}_{4}$ centers) and $\mathrm{LaGaO}_{3}$. Although they have several steps larger than $1.23 \mathrm{eV}$, these steps differ appreciably, so optimizing the potential-limiting step may effectively result in an overpotential decrease.

In Figure 3a we observe that the statistical dispersion of the data increases alongside ESSI, so that good catalysts are usually highly symmetric and, thus, hard to optimize. It is then, when ESSI is close to zero, that scaling relations need to be broken.

\section{Joint analysis of oxygen reduction and evolution by means of ESSI}

Rossmeisl and co-workers [32] noticed that assuming the oxygen reduction reaction (ORR) mechanism to be the inverse of the OER ( $\mathrm{O}_{2} \rightarrow{ }^{*} \mathrm{OOH} \rightarrow{ }^{*} \mathrm{O} \rightarrow{ }^{*} \mathrm{OH} \rightarrow \mathrm{H}_{2} \mathrm{O}$ ), leads to a double volcano activity plot. Because of scaling relations, the OER and ORR activity summits are located at different adsorption energies [24,25,29,32]. This implies that a given surface site can hardly be simultaneously efficient for OER and ORR. This is observed in Figure 4, where ESSI for the OER is plotted against $\eta_{O E R}$ as in Figure 3, and ESSI for the ORR is plotted against $-\eta_{O R R}$.

As shown by Rossmeisl et al [32], there is a "forbidden region" around the ideal catalyst: the bestfit lines in Figure 4 have slopes close to 1 , but the offsets differ by $0.27+0.34=0.61 \mathrm{~V}$. If the OER 


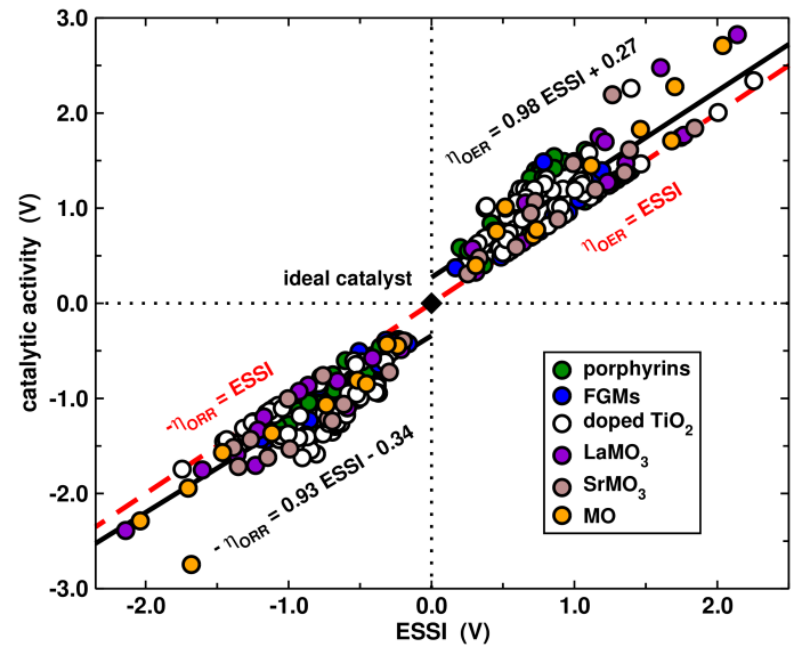

Figure 4. Correlation between ESSI and OER and ORR catalytic activity, defined as $\eta_{\text {OER }}$ and $-\eta_{\text {ORR }}$, respectively. The MAE for the ORR is $0.18 \mathrm{eV}$ and $84 \%$ of the data is contained within an area of $\pm 1.5 \mathrm{MAE}$. The red dashed line describes the points for which $\eta_{O E R}=E S S I$ and $-\eta_{O R R}=E S S I$.

mechanism is indeed the inverse of the ORR, $0.61 \mathrm{~V}$ is the lowest possible overpotential sum (also known as bifunctionality index) as a result of the asymmetry of the electrochemical steps. This agrees well with the experimental fact that bifunctionality indices of $\sim 0.8 \mathrm{~V}$ are observed for active ORR/OER catalysts (measured with linear sweep voltammetry at 10 and $-1 \mathrm{mAcm}^{-2}$ for the OER and the ORR, respectively) $[35,36]$. Note in passing that, as shown in Figure 5 and as a result of assuming inverse mechanisms, the ESSI for ORR and OER are linearly dependent and the slopes of the lines depend on the number of steps larger and smaller than $1.23 \mathrm{eV}$.

\section{Additional considerations}

Before concluding, we would like to emphasize that the analysis here can be influenced by certain additional factors.

First, there is growing awareness in computational electrocatalysis about the impact of solvation in scaling relations and volcano-type

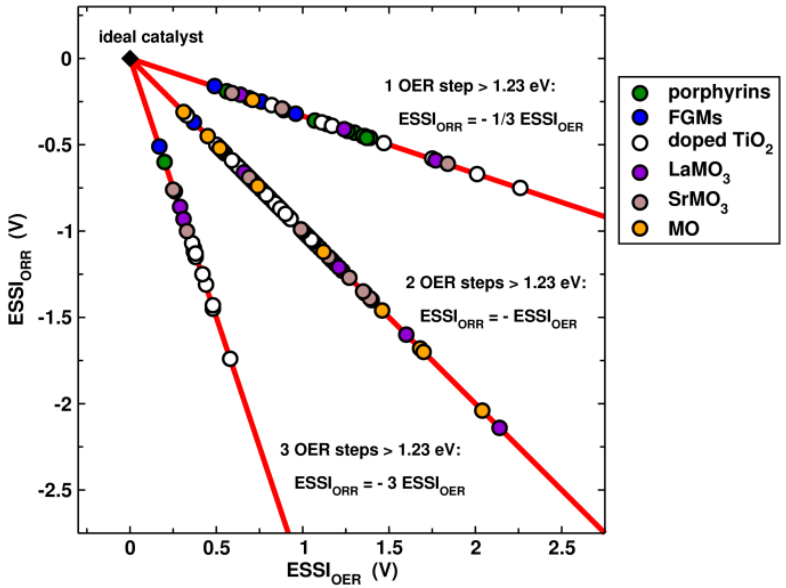

Figure 5. Correlation between $\mathrm{ESSI}_{\mathrm{OER}}$ and $\mathrm{ESSI}_{\mathrm{ORR}}$ for the catalysts considered in this study. The slopes depend on the number of steps larger and smaller than $1.23 \mathrm{eV}$.

activity plots. Recent studies highlight the importance of solvation for the realistic modeling of electrocatalysts [14,25,28,34,37-42]. While regarding solvation as a constant shift to all data points within a trend is still the preferred method to account for solvent effects in electrocatalysis, we believe that catalyst-specific corrections [25,28,37], although computationally more expensive, are required for providing more accurate activity predictions. The same holds for models incorporating an explicit solvent description [37,39,42-46], which provide more accurate results than implicit schemes but are more computationally demanding.

Furthermore, the analysis here assumes that OER and ORR proceed through a single reaction mechanism on all types of materials [19,20,22]. While this is a convenient assumption frequently used in computational electrocatalysis to simplify screening studies, it may not be representative of real (electro)catalytic processes. This has recently been pointed out for $\mathrm{CO}$ hydrogenation during $\mathrm{CO}_{2}$ reduction [14], and the OER [47]: if a certain material splits $\mathrm{O}_{2}$ into $2 * \mathrm{O}$ without prohibitive kinetic barriers, the formation of $* \mathrm{OOH}$ is avoided and the scaling between $* \mathrm{OOH}$ and $* \mathrm{OH}$ does not influence $\eta_{O E R}$. 
There are also some methodological concerns regarding the OER framework used here. For instance, $\mathrm{RuO}_{2}(110)$, an archetypal OER material, is not predicted to be active in a density functional theory (DFT) description at the GGA level. Using DFT+U $[48,49]$ or including structural defects mitigate but do not completely suppress this artifact [50]. Using a new type of scaling relations (not made for several materials using identical simulation parameters, as conventionally done, but for a single material using different simulation parameters) [39], Briquet et al detected an anomaly among the adsorption energies of oxygenates on $\mathrm{RuO}_{2}(110)$, which is likely responsible for the poor prediction of its OER activity. Explicit solvation and exchange-correlation functionals including van der Waals interactions help in correcting the anomaly. Recently, Tripkovic et al have also shown that the OER activities of oxides modelled with DFT $+\mathrm{U}$ and hybrid functionals strongly depend on the values of $U$ and exact exchange used, so the results should be obtained and interpreted with extreme precaution [51].

\section{Summary and outlook}

Here we have discussed the application and reaches of adsorption-energy scaling relations in the context of oxygen electrocatalysis. While substantial computational and experimental efforts have been directed toward identifying OER catalysts that break the $* \mathrm{OOH}$ vs $* \mathrm{OH}$ scaling, our analysis of literature data suggests that this is a necessary yet insufficient condition to design superior catalysts.

From a thermodynamic perspective, the criterion that guarantees efficient electrocatalysis is minimal deviation from the equilibrium potential of the reaction energies of all electrochemical steps [19]. In this regard, we pointed to recent OER computational studies that support this idea, and introduced a new descriptor, the electrochemical-step symmetry index (ESSI). Our analysis of ESSI values explains why high OER activity may be predicted on materials that do not break scaling relations, and why low OER activity may as well be predicted on materials that break those. Furthermore, we extended the ESSI-based analysis to the ORR.

We suggest that future efforts directed to the design of enhanced OER and/or ORR catalysts focus not just on breaking the *OOH vs $* \mathrm{OH}$ scaling but on optimizing ESSI and finding material properties that correlate well with it. In particular, the range bars associated to ESSI and the number of steps larger than $1.23 \mathrm{eV}$ indicate how easy or difficult it is to lower the overpotential of a given material.

Last but not least, note that our conclusions and the ESSI analysis may also be extended to other multistep electrocatalytic reactions such as $\mathrm{CO}_{2}$ reduction, for which breaking the $* \mathrm{CHO}$ vs $* \mathrm{CO}$ scaling is considered paramount [16,21]. Recently, it was suggested that $* \mathrm{CO}$ hydrogenation is likely not the potential-limiting step of $\mathrm{CO}_{2}$ reduction, implying that breaking the scaling between $* \mathrm{CHO}$ vs $* \mathrm{CO}$ might not suffice to enhance $\mathrm{CO}_{2}$ reduction [14].

While adsorption-energy scaling relations are a powerful tool to understand trends and guide computational and experimental studies, we recommend that their exact role on designing superior catalysts be assessed with great caution.

\section{Acknowledgments}

N.G. acknowledges funding from NWO and Shell International Solutions B.V. under the 'Computational Sciences for Energy Research' program. F.C.-V. thanks the Spanish MEC for a Ramón y Cajal research contract (RYC-2015-18996). We thank Prof. John Kitchin and Dr Vladimir Tripkovic for interesting comments and suggestions.

\section{References and recommended reading}

Papers of particular interest, published witihin the period of review, have been highlighted as:

- Paper of special interest

- Paper of outstanding interest 
1. Abild-Pedersen F, Greeley J, Studt F, Rossmeisl J, Munter TR, Moses PG, Skúlason E, Bligaard T, Nørskov JK: Scaling Properties of Adsorption Energies for Hydrogen-Containing Molecules on Transition-Metal Surfaces. Phys Rev Lett (2007) 99(1):016105.

- In this paper scaling relations were first introduced for $\mathrm{C}$ and $\mathrm{CH}_{\mathrm{x}}, \mathrm{N}$ and $\mathrm{NH}_{\mathrm{x}}, \mathrm{O}$ and $\mathrm{OH}$, and $\mathrm{S}$ and $\mathrm{SH}$. The slopes were calculated based on the adsorbates' hydrogen content.

2. Montemore MM, Medlin JW: Scaling relations between adsorption energies for computational screening and design of catalysts. Catal Sci Technol (2014) 4(37483761.

- As well as ref. 3, this paper is a comprehensive review of scaling relations and their applications in catalysis.

3. Greeley J: Theoretical Heterogeneous Catalysis: Scaling Relationships and Computational Catalyst Design. Annual Review of Chemical and Biomolecular Engineering (2016) 7(1):605-635.

- As well as ref. 2, this paper is a comprehensive review of scaling relations and their applications in catalysis.

4. Seh ZW, Kibsgaard J, Dickens CF, Chorkendorff I, Nørskov JK, Jaramillo TF: Combining theory and experiment in electrocatalysis: Insights into materials design. Science (2017) 355(6321).

5. Norskov JK, Bligaard T, Rossmeisl J, Christensen $\mathrm{CH}$ : Towards the computational design of solid catalysts. Nat Chem (2009) 1(1):37-46.

6. Abild-Pedersen F: Computational catalyst screening: Scaling, bond-order and catalysis. Catal Today (2016) 272(Supplement C):6-13.
7. Su H-Y, Sun K, Wang W-Q, Zeng Z, CalleVallejo F, Li W-X: Establishing and Understanding Adsorption-Energy Scaling Relations with Negative Slopes. $J$ Phys Chem Lett (2016) 7(24):5302-5306.

-• This paper uses the formalism in ref. 8 to show that scaling relations with negative slopes exist. Such an intriguing phenomenon is rationalized based on several electronic-structure descriptors.

8. Calle-Vallejo F, Martinez JI, Garcia-Lastra JM, Rossmeisl J, Koper MTM: Physical and Chemical Nature of the Scaling Relations between Adsorption Energies of Atoms on Metal Surfaces. Phys Rev Lett (2012) 108(11).

-• Here scaling relations are extended beyond adsorbed atoms and their hydrogenated counterparts, as in ref. 1. Scaling relations are explained on the basis of a simple mathematical formalism and the slope is shown to depend more generally on electroncounting rules applied to the adsorbates. The same formalism is used in refs. 7 and 9.

9. Calle-Vallejo F, Loffreda D, Koper MTM, Sautet P: Introducing structural sensitivity into adsorption-energy scaling relations by means of coordination numbers. Nat Chem (2015) 7(5):403-410.

- This paper shows that the offset of scaling relations depends on the coordination number of the adsorption sites, while the slope is approximately surface-independent.

10. Calle-Vallejo F, Martínez JI, García-Lastra JM, Sautet P, Loffreda D: Fast Prediction of Adsorption Properties for Platinum Nanocatalysts with Generalized Coordination Numbers. Angew Chem Int Ed (2014) 53(32):8316-8319.

11. Calle-Vallejo F, Pohl MD, Reinisch D, Loffreda D, Sautet P, Bandarenka AS: Why conclusions from platinum model surfaces do not necessarily lead to enhanced nanoparticle catalysts for the oxygen reduction reaction. Chem Sci (2017) 8(3):2283-2289. 
12. Pohl MD, Watzele S, Calle-Vallejo F, Bandarenka AS: Nature of Highly Active Electrocatalytic Sites for the Hydrogen Evolution Reaction at Pt Electrodes in Acidic Media. ACS Omega (2017) 2(11):8141-8147.

13. Tymoczko J, Calle-Vallejo F, Schuhmann W, Bandarenka AS: Making the hydrogen evolution reaction in polymer electrolyte membrane electrolysers even faster. Nat Commun (2016) 7(10990.

14. Calle-Vallejo F, Koper MTM: Accounting for Bifurcating Pathways in the Screening for $\mathrm{CO} 2$ Reduction Catalysts. ACS Catal (2017) 7(10):7346-7351.

-. This article shows that the bifurcation of catalytic pathways should be analyzed before attributing large overpotentials to a given scaling relation.

15. Calle-Vallejo F, Sautet P, Loffreda D: Understanding Adsorption-Induced Effects on Platinum Nanoparticles: An Energy-Decomposition Analysis. $J$ Phys Chem Lett (2014) 3120-3124.

16. Peterson AA, Nørskov JK: Activity Descriptors for $\mathrm{CO} 2$ Electroreduction to Methane on Transition-Metal Catalysts. $J$ Phys Chem Lett (2012) 3(2):251-258.

17. Calle-Vallejo F, Díaz-Morales OA, Kolb MJ, Koper MTM: Why Is Bulk Thermochemistry a Good Descriptor for the Electrocatalytic Activity of Transition Metal Oxides? ACS Catal (2015) 5(2):869873.

18. Fields M, Tsai C, Chen LD, Abild-Pedersen F, Nørskov JK, Chan K: Scaling Relations for Adsorption Energies on Doped Molybdenum Phosphide Surfaces. ACS Catal (2017) 7(4):2528-2534.

19. Man IC, Su H-Y, Calle-Vallejo F, Hansen HA, Martinez JI, Inoglu NG, Kitchin J,
Jaramillo TF, Norskov JK, Rossmeisl J: Universality in Oxygen Evolution Electrocatalysis on Oxide Surfaces. ChemCatChem (2011) 3(7):1159-1165.

- This article extended the findings of ref. 20 to a large number of oxides, showing that the scaling between * $\mathrm{OH}$ and $* \mathrm{OOH}$ is "universal".

20. Koper MTM: Thermodynamic theory of multi-electron transfer reactions: Implications for electrocatalysis. $J$ Electroanal Chem (2011) 660(2):254-260.

- This article was the first to suggest that the scaling relation between ${ }^{*} \mathrm{OH}$ and $* \mathrm{OOH}$ is harmful for the OER and the ORR.

21. Li Y, Sun Q: Recent Advances in Breaking Scaling Relations for Effective Electrochemical Conversion of $\mathrm{CO} 2 . A d v$ Energy Mater (2016) 6(17):1600463.

- This comprehensive review collects various strategies in the literature used to break scaling relations.

22. Rossmeisl J, Qu ZW, Zhu H, Kroes GJ, Nørskov JK: Electrolysis of water on oxide surfaces. $J$ Electroanal Chem (2007) 607(1):83-89.

-. This article outlines the thermodynamic framework used to model the OER.

23. Diaz-Morales O, Ledezma-Yanez I, Koper MTM, Calle-Vallejo F: Guidelines for the Rational Design of Ni-Based Double Hydroxide Electrocatalysts for the Oxygen Evolution Reaction. ACS Catal (2015) 5(9):5380-5387.

24. Calle-Vallejo F, Martinez JI, Rossmeisl J: Density functional studies of functionalized graphitic materials with late transition metals for oxygen reduction reactions. Phys Chem Chem Phys (2011) 13(34):15639-15643.

25. Calle-Vallejo F, Krabbe A, Garcia-Lastra JM: How covalence breaks adsorptionenergy scaling relations and solvation 
restores them. Chem Sci (2017) 8(1):124130.

- This article shows that solvation and metaladsorbate covalence affect the slope of scaling relations. The implications for the ORR and OER modelling are also discussed.

26. García-Mota M, Vojvodic A, Metiu H, Man IC, Su H-Y, Rossmeisl J, Nørskov JK: Tailoring the Activity for Oxygen Evolution Electrocatalysis on Rutile TiO2(110) by Transition-Metal Substitution. ChemCatChem (2011) 3(10):1607-1611.

27. Calle-Vallejo F, Inoglu NG, Su H-Y, Martinez JI, Man IC, Koper MTM, Kitchin JR, Rossmeisl J: Number of outer electrons as descriptor for adsorption processes on transition metals and their oxides. Chem Sci (2013) 4(3):1245-1249.

28. He Z-D, Hanselman S, Chen Y-X, Koper MTM, Calle-Vallejo F: Importance of Solvation for the Accurate Prediction of Oxygen Reduction Activities of Pt-Based Electrocatalysts. J Phys Chem Lett (2017) 8(10):2243-2246.

- Similar to ref. 37, this article shows that, unlike usually assumed, solvation is not constant among Pt alloys. The changes depend on the alloys' composition.

29. Calle-Vallejo F, Martínez JI, García-Lastra JM, Abad E, Koper MTM: Oxygen reduction and evolution at single-metal active sites: Comparison between functionalized graphitic materials and protoporphyrins. Surf Sci (2013) 607(0):47-53.

30. Baran JD, Grönbeck H, Hellman A: Analysis of Porphyrines as Catalysts for Electrochemical Reduction of $\mathrm{O} 2$ and Oxidation of H2O. $\mathrm{J}$ Am Chem Soc (2014) 136(4):1320-1326.
31. Halck NB, Petrykin V, Krtil P, Rossmeisl J: Beyond the volcano limitations in electrocatalysis - oxygen evolution reaction. Phys Chem Chem Phys (2014) 16(27): 13682-13688.

-• This article correlates high OER activity with the breaking of scaling relations on Ni- and Co-doped $\mathrm{RuO}_{2}$.

32. Busch M, Halck NB, Kramm UI, Siahrostami S, Krtil P, Rossmeisl J: Beyond the top of the volcano? - A unified approach to electrocatalytic oxygen reduction and oxygen evolution. Nano Energy (2016) 29(Supplement C):126-135.

- This article features a unified thermodynamic approach for ORR and OER based on scaling relations. It hints toward materials that might overcome the limitations imposed by those relations.

33. Doyle AD, Montoya JH, Vojvodic A: Improving Oxygen Electrochemistry through Nanoscopic Confinement. ChemCatChem (2015) 7(5):738-742.

34. Fortunelli A, Goddard WA, Sha Y, Yu TH, Sementa L, Barcaro G, Andreussi O: Dramatic Increase in the Oxygen Reduction Reaction for Platinum Cathodes from Tuning the Solvent Dielectric Constant. Angew Chem Int Ed (2014) 53(26):6669-6672.

35. Masa J, Xia W, Sinev I, Zhao A, Sun Z, Grützke S, Weide P, Muhler M, Schuhmann $\mathrm{W}$ : MnxOy/NC and CoxOy/NC Nanoparticles Embedded in a NitrogenDoped Carbon Matrix for HighPerformance Bifunctional Oxygen Electrodes. Angew Chem Int Ed (2014) 53(32):8508-8512.

36. Elumeeva K, Masa J, Tietz F, Yang F, Xia W, Muhler M, Schuhmann W: A Simple Approach towards High-Performance Perovskite-Based Bifunctional Oxygen 
Electrocatalysts. ChemElectroChem (2016) 3(1):138-143.

37. Tripkovic V: Thermodynamic assessment of the oxygen reduction activity in aqueous solutions. Phys Chem Chem Phys (2017) 19(43):29381-29388.

- In line with ref. 28 , this article shows that solvation is not constant among transition metals, which has a sizable effect on the modelling of the ORR.

38. Akhade SA, Luo W, Nie X, Asthagiri A, Janik MJ: Theoretical insight on reactivity trends in $\mathrm{CO} 2$ electroreduction across transition metals. Catal Sci Technol (2016) 6(4):1042-1053.

39. Briquet LGV, Sarwar M, Mugo J, Jones G, Calle-Vallejo F: A New Type of Scaling Relations to Assess the Accuracy of Computational Predictions of Catalytic Activities Applied to the Oxygen Evolution Reaction. ChemCatChem (2017) 9(7):1261-1268.

- A special type of scaling relations helps detect and explain anomalous adsorption energies, such as those of OER intermediates on $\mathrm{RuO}_{2}(110)$. Explicit solvation, vdW functionals and volcanoes with *OOH-based descriptors help solve the inconsistency.

40. Sakong S, Groß A: The Importance of the Electrochemical Environment in the Electro-Oxidation of Methanol on Pt(111). ACS Catal (2016) 6(8):5575-5586.

41. Keith JA, Jerkiewicz G, Jacob T: Theoretical Investigations of the Oxygen Reduction Reaction on $\operatorname{Pt}(111)$. ChemPhysChem (2010) 11(13):2779-2794.

42. Herron JA, Morikawa Y, Mavrikakis M: Ab initio molecular dynamics of solvation effects on reactivity at electrified interfaces. Proc Natl Acad Sci U S A (2016) 113(34):E4937-E4945.
43. Clayborne A, Chun H-J, Rankin RB, Greeley J: Elucidation of Pathways for NO Electroreduction on $\operatorname{Pt}(111)$ from First Principles. Angew Chem Int Ed (2015) 54(28):8255-8258.

- In this article a complex electrocatalytic reaction is simulated by explicitly including the solvent and incorporating kinetic barriers.

44. Kolb MJ, Farber RG, Derouin J, Badan C, Calle-Vallejo F, Juurlink LBF, Killelea DR, Koper MTM: Double-Stranded Water on Stepped Platinum Surfaces. Phys Rev Lett (2016) 116(13):136101.

45. Kolb MJ, Wermink J, Calle-Vallejo F, Juurlink LBF, Koper MTM: Initial stages of water solvation of stepped platinum surfaces. Phys Chem Chem Phys (2016) 18(5):3416-3422.

46. de Morais RF, Kerber T, Calle-Vallejo F, Sautet P, Loffreda D: Capturing Solvation Effects at a Liquid/Nanoparticle Interface by Ab Initio Molecular Dynamics: Pt201 Immersed in Water. Small (2016) 12(38):5312-5319.

47. Hessels J, Detz RJ, Koper MTM, Reek JNH: Rational Design Rules for Molecular Water Oxidation Catalysts based on Scaling Relationships. Chemistry - A European Journal (2017) 23(65):1641316418.

- In this article the authors show that the disadvantages of scaling relations can be avoided by changing the reaction mechanism.

48. $\quad \mathrm{Xu} \mathrm{Z}$, Kitchin JR: Tuning oxide activity through modification of the crystal and electronic structure: from strain to potential polymorphs. Phys Chem Chem Phys (2015) 17(43):28943-28949.

49. Xu Z, Rossmeisl J, Kitchin JR: A Linear Response DFT $+U$ Study of Trends in the Oxygen Evolution Activity of Transition 
Metal Rutile Dioxides. $J$ Phys Chem C (2015) 119(9):4827-4833.

- This article analyses the effect of the Hubbard parameter $\mathrm{U}$ on (i) scaling relations between $* \mathrm{O}$, $* \mathrm{OH}$ and $* \mathrm{OOH}$, and (ii) OER activity predictions.

50. Dickens CF, Nørskov JK: A Theoretical Investigation into the Role of Surface Defects for Oxygen Evolution on RuO2. $J$ Phys Chem C (2017) 121(34):18516-18524.

51. Tripkovic V, Hansen HA, García-Lastra JM, Vegge T: Comparative DFT $+\mathrm{U}$ and HSE Study of the Oxygen Evolution Electrocatalysis on Perovskite Oxides. $J$ Phys Chem C (2017).

- This thorough article analyzes the sensitivity of OER activity predictions with respect to (i) the value of the Hubbard parameter for DFT $+\mathrm{U}$, and (ii) the amount of exact exchange in hybrid functionals. 


\title{
Supporting Information for:
}

\section{Does the breaking of adsorption-energy scaling relations guarantee enhanced electrocatalysis?}

\author{
Nitish Govindarajan, Juan M. García-Lastra, Evert Jan Meijer and Federico Calle-Vallejo
}

In Tables S1-S6 we provide all the data used to build Figures 1-3 in the main text. All energies are in $\mathrm{eV}$, whereas $\Omega=\left(\Delta G_{O O H}-\Delta G_{O H}-2.46 \mathrm{eV}\right) / 2 e^{-}$, ESSI ${ }_{\mathrm{OER}}, \mathrm{ESSI}_{\mathrm{ORR}}, \eta_{O E R}$ and $-\eta_{\text {ORR }}$ are in $\mathrm{V}$.

Table S1. OER data for (un)doped $\mathrm{TiO}_{2}$ taken from [1].

\begin{tabular}{|c|c|c|c|c|c|c|c|c|}
\hline Material & $\Delta G_{O}$ & $\Delta G_{O H}$ & $\Delta G_{\mathrm{OOH}}$ & $\Omega$ & $\mathrm{ESSI}_{\mathrm{OER}}$ & $\eta_{O E R}$ & $\mathrm{ESSI}_{\mathrm{ORR}}$ & $-\eta_{O R R}$ \\
\hline $\mathrm{TiO}_{2}$ & 4.60 & 2.07 & 5.08 & 0.27 & 1.07 & 1.30 & -1.07 & -1.39 \\
\hline $\mathrm{V}-\mathrm{TiO}_{2}(5 \mathrm{cM})$ & 2.35 & 1.38 & 4.50 & 0.33 & 0.53 & 0.91 & -0.53 & -0.80 \\
\hline $\mathrm{V}-\mathrm{TiO}_{2}(5 \mathrm{cM})$ & 3.17 & 1.18 & 4.67 & 0.51 & 0.51 & 0.75 & -0.51 & -0.98 \\
\hline $\mathrm{V}-\mathrm{TiO}_{2}(6 \mathrm{cM})$ & 2.76 & 0.38 & 3.97 & 0.56 & 1.14 & 1.02 & -0.38 & -0.84 \\
\hline $\mathrm{V}-\mathrm{TiO}_{2}(6 \mathrm{cM})$ & 3.40 & 1.02 & 4.56 & 0.54 & 1.14 & 1.15 & -0.38 & -0.87 \\
\hline $\mathrm{V}-\mathrm{TiO}_{2}(6 \mathrm{cM})$ & 3.46 & 1.12 & 4.63 & 0.52 & 1.11 & 1.11 & -0.37 & -0.94 \\
\hline $\mathrm{Nb}-\mathrm{TiO}_{2}(5 \mathrm{cM})$ & 1.38 & -0.08 & 3.39 & 0.51 & 0.44 & 0.76 & -1.31 & -1.31 \\
\hline $\mathrm{Nb}-\mathrm{TiO}_{2}(5 \mathrm{cM})$ & 2.14 & 0.23 & 3.74 & 0.52 & 0.52 & 0.67 & -0.52 & -0.99 \\
\hline $\mathrm{Nb}-\mathrm{TiO}_{2}(6 \mathrm{cM})$ & 2.33 & 0.10 & 3.61 & 0.52 & 0.37 & 1.00 & -1.12 & -1.12 \\
\hline $\mathrm{Nb}-\mathrm{TiO}_{2}(6 \mathrm{cM})$ & 2.38 & 0.05 & 3.59 & 0.54 & 0.60 & 1.13 & -0.60 & -1.17 \\
\hline $\mathrm{Nb}-\mathrm{TiO}_{2}(6 \mathrm{cM})$ & 2.69 & 0.29 & 3.80 & 0.54 & 1.17 & 1.19 & -0.39 & -0.93 \\
\hline $\mathrm{Ta}^{-\mathrm{TiO}_{2}}(5 \mathrm{cM})$ & 1.50 & -0.51 & 3.04 & 0.55 & 0.58 & 0.78 & -1.74 & -1.74 \\
\hline $\mathrm{Ta}-\mathrm{TiO}_{2}(5 \mathrm{cM})$ & 1.86 & -0.024 & 3.52 & 0.54 & 0.42 & 0.65 & -1.25 & -1.25 \\
\hline $\mathrm{Ta}^{-\mathrm{TiO}_{2}}(6 \mathrm{cM})$ & 2.33 & 0.07 & 3.60 & 0.53 & 0.38 & 1.02 & -1.15 & -1.15 \\
\hline $\mathrm{Ta}^{-\mathrm{TiO}_{2}}(6 \mathrm{cM})$ & 2.17 & -0.35 & 3.37 & 0.63 & 0.80 & 1.31 & -0.80 & -1.58 \\
\hline $\mathrm{Ta}^{-\mathrm{TiO}_{2}}(6 \mathrm{cM})$ & 2.55 & 0.125 & 3.64 & 0.53 & 0.62 & 1.20 & -0.62 & -1.10 \\
\hline $\mathrm{Cr}-\mathrm{TiO}_{2}(5 \mathrm{cM})$ & 2.43 & 1.85 & 4.87 & 0.28 & 0.92 & 1.20 & -0.92 & -1.18 \\
\hline $\mathrm{Cr}-\mathrm{TiO}_{2}(5 \mathrm{cM})$ & 3.44 & 1.61 & 5.14 & 0.53 & 0.48 & 0.59 & -1.45 & -1.45 \\
\hline $\mathrm{Cr}-\mathrm{TiO}_{2}(6 \mathrm{cM})$ & 2.91 & 1.23 & 4.76 & 0.53 & 0.36 & 0.61 & -1.07 & -1.07 \\
\hline $\mathrm{Cr}-\mathrm{TiO}_{2}(6 \mathrm{cM})$ & 4.14 & 1.72 & 5.23 & 0.52 & 0.84 & 1.20 & -0.84 & -1.54 \\
\hline $\mathrm{Cr}-\mathrm{TiO}_{2}(6 \mathrm{cM})$ & 3.84 & 1.56 & 5.04 & 0.51 & 0.69 & 1.05 & -0.69 & -1.35 \\
\hline 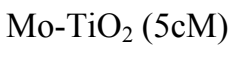 & 0.49 & 0.42 & 3.72 & 0.42 & 2.0 & 1.99 & -0.67 & -1.17 \\
\hline $\mathrm{Mo}^{-\mathrm{TiO}_{2}}(5 \mathrm{cM})$ & 1.46 & 0.61 & 4.16 & 0.54 & 1.46 & 1.45 & -0.49 & -0.61 \\
\hline $\mathrm{Mo}^{-\mathrm{TiO}_{2}}(6 \mathrm{cM})$ & 0.86 & 0.28 & 3.83 & 0.54 & 1.74 & 1.73 & -0.58 & -0.94 \\
\hline $\mathrm{Mo}^{-\mathrm{TiO}_{2}}(6 \mathrm{cM})$ & 2.18 & 0.62 & 4.17 & 0.54 & 0.54 & 0.74 & -0.54 & -0.60 \\
\hline $\mathrm{Mo}^{-\mathrm{TiO}_{2}}(6 \mathrm{cM})$ & 2.35 & 0.58 & 4.10 & 0.53 & 0.53 & 0.53 & -0.53 & -0.64 \\
\hline $\mathrm{W}-\mathrm{TiO}_{2}(5 \mathrm{cM})$ & -0.33 & -0.23 & 3.16 & 0.47 & 1.39 & 2.26 & -1.40 & -1.46 \\
\hline $\mathrm{W}-\mathrm{TiO}_{2}(5 \mathrm{cM})$ & 0.42 & 0.34 & 3.90 & 0.55 & 2.25 & 2.34 & -0.75 & -1.16 \\
\hline $\mathrm{W}-\mathrm{TiO}_{2}(6 \mathrm{cM})$ & 0.26 & 0.05 & 3.50 & 0.49 & 1.10 & 1.58 & -1.10 & -1.17 \\
\hline
\end{tabular}




\begin{tabular}{|c|c|c|c|c|c|c|c|c|}
\hline $\mathrm{W}-\mathrm{TiO}_{2}(6 \mathrm{cM})$ & 1.16 & 0.05 & 3.60 & 0.55 & 0.65 & 1.20 & -0.65 & -1.17 \\
\hline $\mathrm{W}-\mathrm{TiO}_{2}(6 \mathrm{cM})$ & 1.46 & 0.21 & 3.71 & 0.52 & 0.52 & 1.00 & -0.52 & -1.01 \\
\hline $\mathrm{Mn}^{-\mathrm{TiO}_{2}}(5 \mathrm{cM})$ & 3.38 & 1.92 & 4.82 & 0.22 & 0.38 & 0.69 & -1.13 & -1.13 \\
\hline $\mathrm{Mn}-\mathrm{TiO}_{2}(5 \mathrm{cM})$ & 4.22 & 2.06 & 5.07 & 0.27 & 0.88 & 0.92 & -0.88 & -1.38 \\
\hline $\mathrm{Mn}-\mathrm{TiO}_{2}(6 \mathrm{cM})$ & 4.20 & 1.94 & 5.09 & 0.34 & 0.87 & 0.92 & -0.87 & -1.40 \\
\hline $\mathrm{Mn}-\mathrm{TiO}_{2}(6 \mathrm{cM})$ & 4.50 & 2.01 & 5.07 & 0.29 & 1.02 & 1.25 & -1.02 & -1.38 \\
\hline $\mathrm{Mn}^{-\mathrm{TiO}_{2}}(6 \mathrm{cM})$ & 4.48 & 2.01 & 5.10 & 0.31 & 1.01 & 1.24 & -1.01 & -1.41 \\
\hline $\mathrm{Fe}-\mathrm{TiO}_{2}(5 \mathrm{cM})$ & 3.73 & 2.10 & 4.95 & 0.19 & 0.63 & 0.88 & -0.63 & -1.26 \\
\hline $\mathrm{Fe}-\mathrm{TiO}_{2}(5 \mathrm{cM})$ & 4.31 & 2.16 & 5.10 & 0.24 & 0.93 & 0.93 & -0.93 & -1.41 \\
\hline $\mathrm{Fe}-\mathrm{TiO}_{2}(6 \mathrm{cM})$ & 3.81 & 1.55 & 5.06 & 0.48 & 0.67 & 1.03 & -0.67 & -1.29 \\
\hline $\mathrm{Fe}-\mathrm{TiO}_{2}(6 \mathrm{cM})$ & 3.98 & 1.55 & 5.06 & 0.52 & 0.76 & 1.20 & -0.76 & -1.37 \\
\hline $\mathrm{Fe}-\mathrm{TiO}_{2}(5 \mathrm{cM})$ & 3.88 & 1.50 & 4.94 & 0.49 & 0.71 & 1.16 & -0.71 & -1.25 \\
\hline $\mathrm{Ru}-\mathrm{TiO}_{2}(5 \mathrm{cM})$ & 2.15 & 1.05 & 4.19 & 0.34 & 0.81 & 0.80 & -0.27 & -0.50 \\
\hline $\mathrm{Ru}-\mathrm{TiO}_{2}(5 \mathrm{cM})$ & 3.55 & 1.73 & 5.12 & 0.46 & 0.48 & 0.58 & -1.43 & -1.43 \\
\hline $\mathrm{Ru}-\mathrm{TiO}_{2}(6 \mathrm{cM})$ & 2.98 & 0.49 & 4.53 & 0.79 & 0.79 & 0.74 & -0.79 & -0.84 \\
\hline $\mathrm{Ru}-\mathrm{TiO}_{2}(6 \mathrm{cM})$ & 3.83 & 1.42 & 4.96 & 0.54 & 0.69 & 1.19 & -0.69 & -1.27 \\
\hline $\mathrm{Ru}-\mathrm{TiO}_{2}(6 \mathrm{cM})$ & 3.90 & 1.47 & 4.95 & 0.51 & 0.72 & 1.20 & -0.72 & -1.26 \\
\hline $\mathrm{Ir}-\mathrm{TiO}_{2}(5 \mathrm{cM})$ & 1.81 & 0.61 & 3.68 & 0.30 & 0.32 & 0.63 & -0.33 & -0.61 \\
\hline $\mathrm{Ir}^{-\mathrm{TiO}_{2}}(5 \mathrm{cM})$ & 3.45 & 1.75 & 4.68 & 0.23 & 0.45 & 0.53 & -0.50 & -0.99 \\
\hline $\mathrm{Ir}-\mathrm{TiO}_{2}(6 \mathrm{cM})$ & 2.72 & 1.13 & 4.64 & 0.52 & 0.52 & 0.67 & -0.52 & -0.95 \\
\hline $\mathrm{Ir}-\mathrm{TiO}_{2}(6 \mathrm{cM})$ & 3.78 & 1.44 & 4.94 & 0.52 & 0.65 & 1.11 & -0.66 & -1.25 \\
\hline $\mathrm{Ir}-\mathrm{TiO}_{2}(6 \mathrm{cM})$ & 3.64 & 1.35 & 4.86 & 0.52 & 0.59 & 1.06 & -0.59 & -1.17 \\
\hline $\mathrm{Ni}^{-\mathrm{TiO}_{2}}(5 \mathrm{cM})$ & 4.55 & 2.03 & 4.80 & 0.15 & 1.04 & 1.29 & -1.04 & -1.10 \\
\hline $\mathrm{Ni}^{-\mathrm{TiO}_{2}}(5 \mathrm{cM})$ & 4.59 & 2.08 & 5.12 & 0.14 & 1.06 & 1.15 & -1.06 & -1.43 \\
\hline $\mathrm{Ni}-\mathrm{TiO}_{2}(6 \mathrm{cM})$ & 4.27 & 2.03 & 5.31 & 0.41 & 0.90 & 1.01 & -0.90 & -1.62 \\
\hline $\mathrm{Ni}-\mathrm{TiO}_{2}(6 \mathrm{cM})$ & 4.57 & 2.08 & 5.08 & 0.27 & 1.05 & 1.25 & -1.05 & -1.39 \\
\hline $\mathrm{Ni}-\mathrm{TiO}_{2}(6 \mathrm{cM})$ & 4.47 & 2.04 & 5.06 & 0.28 & 1.00 & 1.19 & -1.00 & -1.37 \\
\hline
\end{tabular}


Table S2. OER/ORR data for porphyrins taken from [2].

\begin{tabular}{|c|c|c|c|c|c|c|c|c|}
\hline Metal center-ring ligand & $\Delta G_{O}$ & $\Delta G_{O H}$ & $\Delta G_{O O H}$ & $\Omega$ & $\mathrm{ESSI}_{\mathrm{OER}}$ & $\eta_{O E R}$ & $\mathrm{ESSI}_{\mathrm{ORR}}$ & $-\eta_{O R R}$ \\
\hline $\mathrm{Cr}-\mathrm{H}$ & 0.85 & 0.26 & 3.53 & 0.40 & 0.81 & 1.45 & -0.81 & -0.97 \\
\hline $\mathrm{Cr}-\mathrm{F}$ & 1.00 & 0.38 & 3.63 & 0.39 & 0.73 & 1.40 & -0.73 & -0.85 \\
\hline $\mathrm{Cr}-\mathrm{OH}$ & 0.76 & 0.22 & 3.49 & 0.40 & 0.85 & 1.50 & -0.85 & -1.01 \\
\hline $\mathrm{Cr}-\mathrm{CH}_{3}$ & 0.61 & 0.18 & 3.33 & 0.35 & 0.92 & 1.49 & -0.92 & -1.05 \\
\hline $\mathrm{Cr}-\mathrm{BH}_{2}$ & 0.94 & 0.36 & 3.58 & 0.38 & 0.76 & 1.41 & -0.76 & -0.87 \\
\hline $\mathrm{Cr}-\mathrm{NH}_{2}$ & 0.60 & 0.10 & 3.33 & 0.38 & 0.92 & 1.49 & -0.93 & -1.13 \\
\hline $\mathrm{Mn}-\mathrm{H}$ & 0.93 & 0.27 & 3.53 & 0.39 & 0.76 & 1.36 & -0.76 & -0.96 \\
\hline $\mathrm{Mn}-\mathrm{F}$ & 1.13 & 0.46 & 3.70 & 0.39 & 1.34 & 1.34 & -0.45 & -0.77 \\
\hline $\mathrm{Mn}-\mathrm{OH}$ & 0.74 & 0.23 & 3.51 & 0.41 & 0.86 & 1.54 & -0.86 & -1.01 \\
\hline $\mathrm{Mn}-\mathrm{CH}_{3}$ & 0.74 & 0.18 & 3.39 & 0.37 & 0.86 & 1.41 & -0.86 & -1.05 \\
\hline $\mathrm{Mn}-\mathrm{BH}_{2}$ & 1.41 & 0.75 & 3.94 & 0.37 & 1.30 & 1.30 & -0.43 & -0.56 \\
\hline $\mathrm{Mn}-\mathrm{NH}_{2}$ & 0.46 & -0.05 & 3.18 & 0.38 & 1.00 & 1.49 & -1.00 & -1.28 \\
\hline Fe-H & 1.19 & 0.63 & 3.77 & 0.34 & 1.36 & 1.36 & -0.45 & -0.67 \\
\hline $\mathrm{Fe}-\mathrm{F}$ & 1.37 & 0.68 & 3.85 & 0.36 & 1.26 & 1.26 & -0.42 & -0.55 \\
\hline $\mathrm{Fe}-\mathrm{OH}$ & 1.07 & 0.48 & 3.62 & 0.34 & 0.69 & 1.31 & -0.69 & -0.75 \\
\hline $\mathrm{Fe}-\mathrm{CH}_{3}$ & 1.10 & 0.57 & 3.73 & 0.35 & 1.39 & 1.39 & -0.46 & -0.70 \\
\hline $\mathrm{Fe}-\mathrm{BH}_{2}$ & 1.51 & 0.88 & 4.09 & 0.38 & 1.35 & 1.35 & -0.45 & -0.59 \\
\hline $\mathrm{Fe}-\mathrm{NH}_{2}$ & 0.89 & 0.34 & 3.45 & 0.32 & 0.78 & 1.32 & -0.78 & -0.89 \\
\hline $\mathrm{Co}-\mathrm{H}$ & 2.30 & 1.21 & 4.09 & 0.21 & 0.56 & 0.56 & -0.19 & -0.40 \\
\hline Co-F & 1.97 & 1.04 & 4.09 & 0.29 & 0.89 & 0.89 & -0.30 & -0.40 \\
\hline $\mathrm{Co}-\mathrm{OH}$ & 1.65 & 0.88 & 3.95 & 0.31 & 1.07 & 1.07 & -0.36 & -0.46 \\
\hline $\mathrm{Co}-\mathrm{CH}_{3}$ & 2.14 & 1.00 & 4.07 & 0.30 & 0.69 & 0.69 & -0.23 & -0.38 \\
\hline $\mathrm{Co}-\mathrm{BH}_{2}$ & 2.47 & 1.24 & 4.29 & 0.29 & 0.20 & 0.58 & -0.60 & -0.60 \\
\hline $\mathrm{Co}-\mathrm{NH}_{2}$ & 1.26 & 0.77 & 3.86 & 0.31 & 1.37 & 1.37 & -0.46 & -0.74 \\
\hline $\mathrm{Ni}-\mathrm{H}$ & 3.66 & 1.82 & 4.85 & 0.28 & 0.60 & 0.61 & -0.60 & -1.16 \\
\hline $\mathrm{Ni}-\mathrm{F}$ & 3.43 & 1.85 & 4.93 & 0.31 & 0.41 & 0.62 & -1.25 & -1.25 \\
\hline $\mathrm{Ni}-\mathrm{OH}$ & 3.21 & 1.58 & 4.78 & 0.37 & 0.37 & 0.40 & -1.10 & -1.10 \\
\hline $\mathrm{Ni}-\mathrm{CH}_{3}$ & 3.82 & 1.84 & 4.6 & 0.15 & 0.68 & 0.75 & -0.68 & -0.91 \\
\hline $\mathrm{Ni}-\mathrm{BH}_{2}$ & 3.85 & 1.93 & 4.78 & 0.20 & 0.70 & 0.70 & -0.70 & -1.10 \\
\hline $\mathrm{Ni}-\mathrm{NH}_{2}$ & 3.10 & 1.32 & 4.46 & 0.34 & 0.26 & 0.55 & -0.77 & -0.77 \\
\hline $\mathrm{Cu}-\mathrm{H}$ & 4.12 & 2.07 & 5.07 & 0.27 & 0.83 & 0.84 & -0.83 & -1.38 \\
\hline $\mathrm{Cu}-\mathrm{F}$ & 4.15 & 2.04 & 5.01 & 0.25 & 0.85 & 0.88 & -0.85 & -1.33 \\
\hline $\mathrm{Cu}-\mathrm{OH}$ & 3.69 & 1.62 & 4.94 & 0.43 & 0.42 & 0.84 & -1.25 & -1.25 \\
\hline $\mathrm{Cu}-\mathrm{CH}_{3}$ & 3.76 & 1.83 & 4.89 & 0.30 & 0.65 & 0.69 & -0.65 & -1.20 \\
\hline $\mathrm{Cu}-\mathrm{BH}_{2}$ & 4.61 & 11.77 & 4.98 & 0.37 & 1.07 & 1.61 & -1.08 & -1.30 \\
\hline $\mathrm{Cu}-\mathrm{NH}_{2}$ & 2.69 & 0.92 & 4.48 & 0.55 & 0.55 & 0.56 & -0.55 & -0.80 \\
\hline
\end{tabular}


Table S3. OER/ORR data for $\mathrm{SrMO}_{3}$, taken from [3-5].

\begin{tabular}{lcccccccc}
\hline \multicolumn{1}{c}{ Material } & $\Delta G_{O}$ & $\Delta G_{O H}$ & $\Delta G_{\text {OOH }}$ & $\Omega$ & $\mathrm{ESSI}_{\text {OER }}$ & $\eta_{\text {OER }}$ & $\mathrm{ESSI}_{\text {ORR }}$ & $-\eta_{\text {ORR }}$ \\
\hline $\mathrm{SrScO}_{3}$ & 5.23 & 2.38 & 5.21 & 0.18 & 1.38 & 1.61 & -1.39 & -1.52 \\
$\mathrm{SrTiO}_{3}$ & 3.91 & 1.61 & 4.90 & 0.42 & 0.72 & 1.07 & -0.73 & -1.22 \\
$\mathrm{SrVO}_{3}$ & -0.07 & 0.13 & 3.35 & 0.38 & 1.26 & 2.19 & -1.27 & -1.43 \\
$\mathrm{SrCrO}_{3}$ & 0.92 & 0.75 & 3.99 & 0.39 & 1.84 & 1.84 & -0.61 & -1.06 \\
$\mathrm{SrMnO}_{3}$ & 2.29 & 1.21 & 4.41 & 0.37 & 0.88 & 0.88 & -0.29 & -0.72 \\
$\mathrm{SrFeO}_{3}$ & 2.98 & 1.67 & 4.70 & 0.28 & 0.33 & 0.47 & -1.00 & -1.00 \\
$\mathrm{SrCoO}_{3}$ & 3.00 & 1.54 & 4.44 & 0.22 & 0.25 & 0.31 & -0.76 & -0.76 \\
$\mathrm{SrNiO}_{3}$ & 3.84 & 2.17 & 4.92 & 0.15 & 0.69 & 0.94 & -0.69 & -1.24 \\
$\mathrm{SrCuO}_{3}$ & 4.75 & 2.32 & 5.31 & 0.26 & 1.14 & 1.19 & -1.15 & -1.62 \\
$\mathrm{SrZnO}_{3}$ & 5.16 & 2.56 & 5.40 & 0.19 & 1.35 & 1.37 & -1.35 & -1.72 \\
$\mathrm{SrGeO}_{3}$ & 4.44 & 1.74 & 5.22 & 0.51 & 0.99 & 1.47 & -0.99 & -1.53 \\
$\mathrm{SrRuO}_{3}$ & 2.26 & 1.11 & 4.09 & 0.26 & 0.59 & 0.59 & -0.20 & -0.40 \\
\hline
\end{tabular}


Table S4. OER/ORR data for $\mathrm{LaMO}_{3}$, taken from [3-5].

\begin{tabular}{lcccccccc}
\hline Material & $\Delta G_{O}$ & $\Delta G_{O H}$ & $\Delta G_{\text {OOH }}$ & $\Omega$ & ESSI OER & $\eta_{\text {OER }}$ & ESSI ORR & $-\eta_{\text {ORR }}$ \\
\hline $\mathrm{LaScO}_{3}$ & 4.80 & 1.82 & 4.88 & 0.30 & 1.17 & 1.75 & -1.17 & 1.75 \\
$\mathrm{LaTiO}_{3}$ & -1.82 & -1.16 & 2.23 & 0.46 & 2.14 & 2.82 & -2.14 & 2.82 \\
$\mathrm{LaVO}_{3}$ & -0.74 & -0.22 & 2.95 & 0.36 & 1.60 & 2.48 & -1.60 & 2.48 \\
$\mathrm{LaCrO}_{3}$ & 0.69 & 0.56 & 3.69 & 0.33 & 1.76 & 1.76 & -0.59 & 1.77 \\
$\mathrm{LaMnO}_{3}$ & 1.39 & 0.65 & 3.85 & 0.37 & 1.23 & 1.24 & -0.41 & 1.24 \\
$\mathrm{LaFeO}_{3}$ & 2.74 & 1.25 & 4.55 & 0.42 & 0.29 & 0.57 & -0.86 & 0.57 \\
$\mathrm{LaCoO}_{3}$ & 2.22 & 1.49 & 4.50 & 0.27 & 0.66 & 1.05 & -0.66 & 1.05 \\
$\mathrm{LaNiO}_{3}$ & 3.09 & 1.54 & 4.61 & 0.30 & 0.31 & 0.32 & -0.93 & 0.33 \\
$\mathrm{LaCuO}_{3}$ & 4.92 & 2.42 & 5.39 & 0.26 & 1.23 & 1.27 & -1.23 & 1.27 \\
$\mathrm{LaZnO}_{3}$ & 5.18 & 2.48 & 5.27 & 0.17 & 1.36 & 1.47 & -1.36 & 1.47 \\
$\mathrm{LaGaO}_{3}$ & 4.88 & 1.95 & 5.02 & 0.30 & 1.21 & 1.70 & -1.21 & 1.70 \\
$\mathrm{LaRuO}_{3}$ & 1.87 & 0.74 & 3.74 & 0.27 & 0.64 & 0.64 & -0.21 & 0.64 \\
\hline
\end{tabular}


Table S5. OER/ORR data for MO, taken from [4,5].

\begin{tabular}{lcccccccc}
\hline Material & $\Delta G_{O}$ & $\Delta G_{O H}$ & $\Delta G_{\text {OOH }}$ & $\Omega$ & $\mathrm{ESSI}_{\text {OER }}$ & $\eta_{\text {OER }}$ & $\mathrm{ESSI}_{\mathrm{ORR}}$ & $-\eta_{\text {ORR }}$ \\
\hline $\mathrm{CaO}$ & 5.38 & 2.32 & 5.04 & 0.13 & 1.46 & 1.82 & -1.46 & 1.83 \\
$\mathrm{ScO}$ & -0.90 & -1.52 & 1.98 & 0.52 & 1.69 & 1.70 & -1.68 & 1.71 \\
$\mathrm{TiO}$ & -1.61 & -1.05 & 2.32 & 0.46 & 2.03 & 2.71 & -2.04 & 2.71 \\
$\mathrm{VO}$ & -0.94 & -0.71 & 2.56 & 0.41 & 1.70 & 2.27 & -1.70 & 2.28 \\
$\mathrm{CrO}$ & 0.22 & -0.13 & 2.90 & 0.29 & 1.12 & 1.44 & -1.12 & 1.45 \\
$\mathrm{MnO}$ & 1.42 & 0.42 & 3.66 & 0.39 & 0.52 & 1.01 & -0.52 & 1.01 \\
$\mathrm{FeO}$ & 1.76 & 0.38 & 3.75 & 0.45 & 0.45 & 0.76 & -0.45 & 0.76 \\
$\mathrm{CoO}$ & 1.98 & 0.78 & 3.92 & 0.34 & 0.71 & 0.71 & -0.24 & 0.71 \\
$\mathrm{NiO}$ & 2.49 & 1.03 & 4.12 & 0.31 & 0.31 & 0.40 & -0.31 & 0.40 \\
$\mathrm{CuO}$ & 3.93 & 2.00 & 4.75 & 0.14 & 0.74 & 0.77 & -0.74 & 0.77 \\
\hline
\end{tabular}


Table S6. OER/ORR data for FGM [6,7].

\begin{tabular}{lcccccccc}
\hline Metal center & $\Delta G_{O}$ & $\Delta G_{O H}$ & $\Delta G_{\text {OOH }}$ & $\Omega$ & ESSI $_{\text {OER }}$ & $\eta_{\text {OER }}$ & ESSI $_{\text {ORR }}$ & $-\eta_{\text {ORR }}$ \\
\hline $\mathrm{Cr}$ & 0.89 & 0.35 & 3.60 & 0.40 & 0.78 & 1.49 & -0.78 & 1.49 \\
$\mathrm{Mn}$ & 1.89 & 0.88 & 4.08 & 0.37 & 0.95 & 0.96 & -0.32 & 0.96 \\
$\mathrm{Fe}$ & 2.11 & 1.03 & 4.11 & 0.30 & 0.76 & 0.76 & -0.25 & 0.76 \\
$\mathrm{Co}$ & 2.93 & 1.22 & 4.11 & 0.21 & 0.48 & 0.48 & -0.16 & 0.49 \\
$\mathrm{Ni}$ & 4.16 & 2.14 & 4.91 & 0.15 & 0.85 & 0.92 & -0.85 & 0.92 \\
$\mathrm{Cu}$ & 4.52 & 2.31 & 5.11 & 0.17 & 1.03 & 1.08 & -1.03 & 1.09 \\
$\mathrm{Ru}$ & 1.72 & 0.58 & 3.63 & 0.30 & 0.37 & 0.68 & -0.37 & 0.68 \\
$\mathrm{Rh}$ & 2.84 & 1.23 & 4.19 & 0.25 & 0.17 & 0.37 & -0.51 & 0.37 \\
$\mathrm{Pd}$ & 4.65 & 2.50 & 5.08 & 0.05 & 1.09 & 1.28 & -1.10 & 1.28 \\
$\mathrm{Ag}$ & 4.77 & 2.52 & 5.12 & 0.07 & 1.16 & 1.30 & -1.16 & 1.30 \\
$\mathrm{Ir}$ & 2.41 & 1.24 & 4.26 & 0.28 & 0.32 & 0.61 & -0.32 & 0.62 \\
$\mathrm{Pt}$ & 4.61 & 2.42 & 5.11 & 0.11 & 1.08 & 1.19 & -1.08 & 1.19 \\
$\mathrm{Au}$ & 4.84 & 2.62 & 5.11 & 0.01 & 1.19 & 1.40 & -1.19 & 1.39 \\
\hline
\end{tabular}

\section{References}

1. García-Mota M, Vojvodic A, Metiu H, Man IC, Su H-Y, Rossmeisl J, Nørskov JK: Tailoring the Activity for Oxygen Evolution Electrocatalysis on Rutile TiO2(110) by Transition-Metal Substitution. ChemCatChem (2011) 3(10):1607-1611.

2. Calle-Vallejo F, Krabbe A, Garcia-Lastra JM: How covalence breaks adsorption-energy scaling relations and solvation restores them. Chem Sci (2017) 8(1):124-130.

3. Man IC, Su H-Y, Calle-Vallejo F, Hansen HA, Martinez JI, Inoglu NG, Kitchin J, Jaramillo TF, Norskov JK, Rossmeisl J: Universality in Oxygen Evolution Electrocatalysis on Oxide Surfaces. ChemCatChem (2011) 3(7):1159-1165.

4. Calle-Vallejo F, Díaz-Morales OA, Kolb MJ, Koper MTM: Why Is Bulk Thermochemistry a Good Descriptor for the Electrocatalytic Activity of Transition Metal Oxides? ACS Catal (2015) 5(2):869873.

5. Calle-Vallejo F, Inoglu NG, Su H-Y, Martinez JI, Man IC, Koper MTM, Kitchin JR, Rossmeisl J: Number of outer electrons as descriptor for adsorption processes on transition metals and their oxides. Chem Sci (2013) 4(3):1245-1249.

6. Calle-Vallejo F, Martínez JI, García-Lastra JM, Abad E, Koper MTM: Oxygen reduction and evolution at single-metal active sites: Comparison between functionalized graphitic materials and protoporphyrins. Surf Sci (2013) 607(0):47-53.

7. Calle-Vallejo F, Martinez JI, Rossmeisl J: Density functional studies of functionalized graphitic materials with late transition metals for oxygen reduction reactions. Phys Chem Chem Phys (2011) 13(34):15639-15643. 